\section{Revijalni članak}

\section{ULTRAZVUK PLUĆA - DRUGI DEO (ULTRAZVUK PLUĆA deo 2)}

\author{
Marija Milenković', Jovana Stanisavljević, \\ Adi Hadžibegović, Gregor Prosen ${ }^{2}$, \\ Dragan Mašulović, Milica Stojadinović
}

${ }^{1}$ Centar za anesteziologiju, Klinički centar Srbije, Beograd, Srbija ${ }^{2}$ Storitve-Enote-Nujna Medicinska pomoč, Zdravstveni dom dr. Adolfa Drolca, Maribor, Slovenija

${ }^{3}$ Centar za radiologiju i MR, Klinički centar Srbije, Beograd, Srbija

\section{Sažetak}

Klinička upotreba ultrazvuka pluća (lung ultrasound - LUS), u hitnim stanjima i pri lečenju kritično obolelih, poprima sve veći značaj i sve više se proučava. LUS je neinvazivna, real-time metoda, jednostavna i dostupna "pored kreveta bolesnika" tehnika (bedside), ekonomična, nema zračenja niti komplikacija. Prednosti LUS-a mogu da dovedu do smanjenja potrebe za radiografijom pluća i kompjuterizovanom tomografijom. Prva Međunarodna koncenzus konferencija za ultrazvuk pluća (International Consensus Conferention of Lung Ultrasound ICC-LUS) dala je preporuke za jedinstveni pristup i termine za šest glavnih polja LUS-a. BLUE protokol (Bedside Lung Ultrasound in Emergency Protocol) prvi je LUS sistematski pristup u dijagnostici pleuralne i plućne patologije. Ovaj protokol pomaže u diferencijalnoj dijagnozi akutne dispneje (plućnog edema, pneumonije, akutnog respiratornog distres sindroma, plućne embolije, pleuralnog izliva ili pneumotoraksa). Ultrazvuk pluća, u cilju dijagnostike pneumotoraksa, postao je i standardni deo proširenog ultrazvučnog protokola za traumu (Extended Focused Assessment by Sonography for Trauma - E-FAST). Tumačenje ultrazvučnog nalaza na plućima se zasniva na identifikaciji glavnih patoloških supstrata plućnog parenhima: intersticijalni sindrom, intersticijalno-alveolarni sindrom, alveolarni sindrom / konsolidacija, pleuralni izliv i pneumotoraks.

Ključne reči: ultrazvuk pluća; BLUE protokol; E-FAST; patološki supstrat

\section{Uvod}

$\mathrm{K}$ linička upotreba ultrazvuka pluća (lung ultrasound - LUS) ima brojne prednosti nad ostalim dijagnostičkim metodama i poprima značaj u diferencijalnoj dijagnostici akutne respiratorne insuficijencije. Radiografija pluća je di-

Autor za korespondenciju: Marija Milenković, Centar za anesteziologiju, Klinički centar Srbije, Pasterova 2, 11000 Beograd, Telefon: +381658266740, E-mail:smgk055@gmail.com

\section{Review article}

\section{LUNG ULTRASOUND - PART TWO (LUNG ULTRASOIND part 2)}

\author{
Marija Milenković, Jovana Stanisavljević, \\ Adi Hadžibegovićl, Gregor Prosen², \\ Dragan Mašulović, Milica Stojadinović ${ }^{3}$
}

${ }^{1}$ Center for anesthesia, Clinical Center Serbia, Belgrade, Serbia ${ }^{2}$ Storitve-Enote-Nujna Medicinska pomoč, Zdravstveni dom dr. Adolfa Drolca, Maribor, Slovenia

${ }^{3}$ Center for radiology and MRI, Clinical Center Serbia, Belgrade, Serbia

\section{Summary}

Clinical use of lung ultrasound (LUS) in emergency and critical care is studied extensively. LUS is a non-invasive, real-time method, easily available at bedside, economical, free of radiation hazard and free of complications. All these features make LUS useful in reducing need for bedside chest radiography and computed tomography. The First International Conference on Lung Ultrasound (ICC-LUS) recommended approach to six major areas of LUS. The BLUE protocol (Bedside Lung Ultrasound and Emergency Protocol) is the first LUS-based systematic approach in diagnosing pleural and lung pathology. This protocol helps to differentiate features of acute dyspnea (pulmonary edema, pneumonia, acute respiratory distress syndrome, pulmonary embolism, pleural effusion or pneumothorax). LUS for pneumothorax diagnosis has become the standard part of the Extended Focused Assessment by Sonography for Trauma (E-FAST). Interpretation of lung ultrasound findings is based on the identification of the main pathological substrates of pulmonary parenchyma: interstitial syndrome, interstitial-alveolar syndrome, alveolar syndrome / consolidation, pleural effusion and pneumothorax.

Key words: lung ultrasound; BLUE protocol; E-FAST; pathological substrate

jagnostička metoda koja se uz anamnezu i status standardno najčešće koristi u dijagnostici nastale dispneje. Međutim, često postoji potreba i za kompjuterizovanom tomografijom, kao zlatnim standardom. Ovi dijagnostički postupci mogu da budu od velike koristi pri lečenju, ali sa druge strane imaju i mnogo mana. To su: velike količi-

Corresponding author: Marija Milenković, Centar za anesteziologiju, Klinički centar Srbije, Pasterova 2, 11000 Beograd, Telephone: +381658266740, E-mail: smgk055@gmail.co 
ne zračenja koje pacijent primi tokom snimanja, ograničena upotreba kod trudnica, dece i agitiranih pacijenata, potreba za većim brojem edukovanog osoblja i transport pacijenta sa odeljenja do uređaja za snimanje, što može da bude rizično za kritično obolele pacijente. LUS je neinvazivna metoda, ekonomična, pristupačna i bezbedna, nema komplikacija i zračenja, sa istovremenim uvidom u rezultat pretrage. Prva Međunarodna koncenzus konferencija za ultrazvuk pluća (International Concesus Conferention of Lung Ultrasound - ICC-LUS) dala je preporuke za jedinstveni pristup i termine za šest glavnih polja LUS ${ }^{1}$. Uvođenje BLUE protokola, kao vodiča za dijagnostiku akutne respiratorne insuficijencije, ima za cilj da smanji primenu radiografije pluća i srca i CT-a grudnog koša u jedinici intezivnog lečenja ${ }^{2}$. Ultrazvuk pluća, u cilju dijagnostike pneumotoraksa, postao je i standardni deo proširenog ultrazvučnog protokola za traumu (Extended Focused Assessment by Sonography for Trauma - E-FAST) $)^{3,4}$. Tumačenje ultrazvučnog nalaza na plućima se zasniva na identifikaciji glavnih patoloških supstrata na nivou plućnog parenhima, kao što su intersticijalni sindrom, intersticijalno-alveolarni sindrom, alveolarni sindrom/konsolidacija, pleuralni izliv i pneumotoraks.

\section{Šta treba da znamo pre početka? (3P)}

3P predstavlja jednostavnu tehniku memorisanja, započinjanja i izvođenja ultrazvučnog pregleda, uključujći i LUS. Obuhvata Probe - sondu, Position - poziciju za akustički prozor i Picture sliku patološkog supstrata (Slika 1).

Prilikom pregleda zida grudnog koša i plućnog parenhima, koristi se visokofrekventna linearna sonda (5-17 MHz). Za evaluaciju pluća interkostalnim, subkostalnim i parasternalnim pristupom je najprikladnija konveksna sonda (3,5-5 MHz) ili sektorska sonda sa optimalnom penetracijom. Pregled se radi u M ili B modu, u zavisnosti od indikacije.

Prednjom i zadnjom aksilarnom linijom uz sternum i kičmeni stub, grudni koš je podeljen na vertikalna polja. Povlačenjem linije kroz sredinu grudnog koša, deli se i na poprečna polja. Tako se dobija 12 polja na grudnom košu, a oni odgovaraju plućnim lobusima.

LUS je zasnovan na postojanju artefakata prilikom prolaska ultrazvučnih talasa. „A linije”, „B linije” i „klizanje” pleure su nalazi koji upućuju na razne patološke supstrate u plućnom parenhimu.

\section{Ultrazvučno tumačenje patološkog supstrata na plućima}

Normalna pluća

Normalan nalaz pluća na ultrazvuku karakteriše prisustvo „klizanja” pleure, vidljive „A linije” i odsustvo „B linija” (Slika 2).

Intersticijalni sindrom

Intersticijalni sindrom označava stanje u kojem intersticijum sadrži više tečnosti, odnosno edem pluća koji može da bude posledica hemodinamskog preopterećenja - edem pluća u insuficijenciji levog srca ili povećane propustljivosti kapilara u ARDS-u. Ultrazvučno su vidljive „B-linije” obostrano, a vizualizuju se na $7 \mathrm{~mm}^{5}$ (Slika 3 ).

Intersticijalno-alveolarni sindrom

Ovaj sindrom se odlikuje još većom količinom tečnosti u intersticijumu, koja je delom prisutna i u alveolama. Vidljive „B linije” su prisutne jednostrano, zastupljene su više nego u intersticijalnom sindromu, zgusnuto su raspoređene, a ponekad i konfluiraju (Slika 4).

\section{Alveolarni sindrom}

Označava konsolidaciju plućnog parenhima u kojem su alveole u celosti ispunjene tečnim sadržajem (eksudat, transudat, krv, voda) i ne postoji aeracija alveola. „B linije” se vizualizuju na $3 \mathrm{~mm}^{5}$. Karakterističan ultrazvučni nalaz je ehogen, podseća na tkivo jetre, pa se naziva znak hepatizacije (Slika 5).

\section{Pleuralni izliv}

Pleuralni izliv označava prisustvo tečnog sadržaja (transudat, eksudat, krv, gnoj) u pleuralnoj šupljini. Ultrazvučno se vidi kao anehogeni prostor. U nekim slučajevima može da se vidi i kao ehogeno područje, ukoliko se radi o eksudatu (Slika 6).

\section{Pneumotoraks}

Pneumotoraks predstavlja prisustvo vazduha u pleuralnom prostoru. U normalnim plućima, kretanje visceralne preko parijetalne pleure, u skladu sa srčanom radnjom i respiratornim ciklusom, ultrazvučno se označava kako znak „klizanja” pluća („lung sliding”) na B modu, a kao znak „morske obale” („seashore sign”) na M modu (Slika 7). Ultrazvučni nalaz pneumotoraksa, posledično, karakteriše odsustvo „klizanja” pluća. Prikaz granice pneumotoraksa, odnosono mesta gde se ponovo uočava „lung sliding” je vrlo specifičan znak za pneumotoraks. Izostanak prikaza „klizanja” pleure, uz nalaz „A linija”, zajedno sa znakom prikaza granice pneumotoraksa, ima visoku senzitivnost i specifičnost za dijagnostiku pneumotoraksa ${ }^{6}$. 


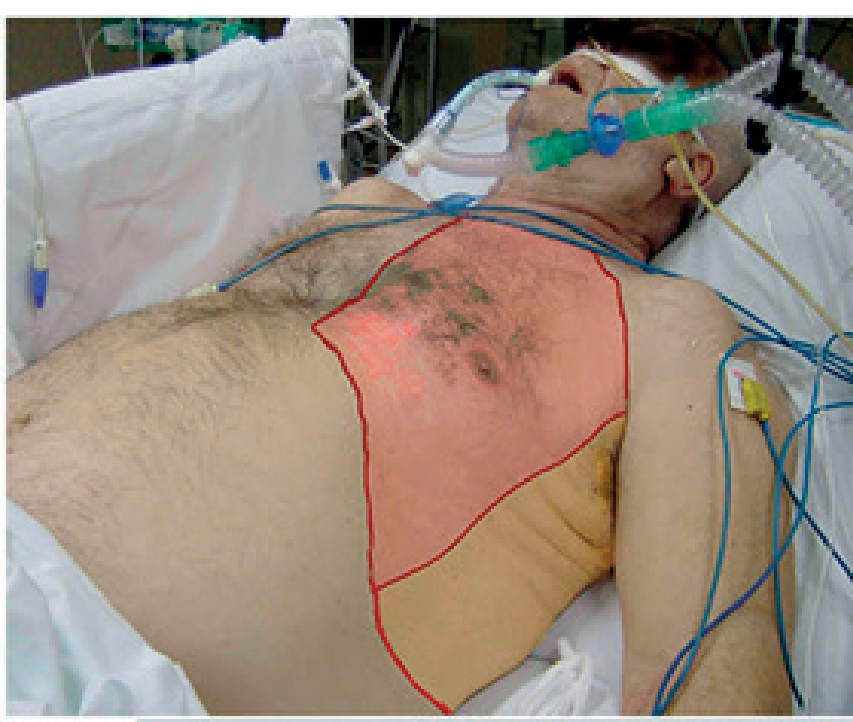

STATION GOALS

To identify potential pleural effusion, pneumothorax pneumonia or pulmonary cedema.

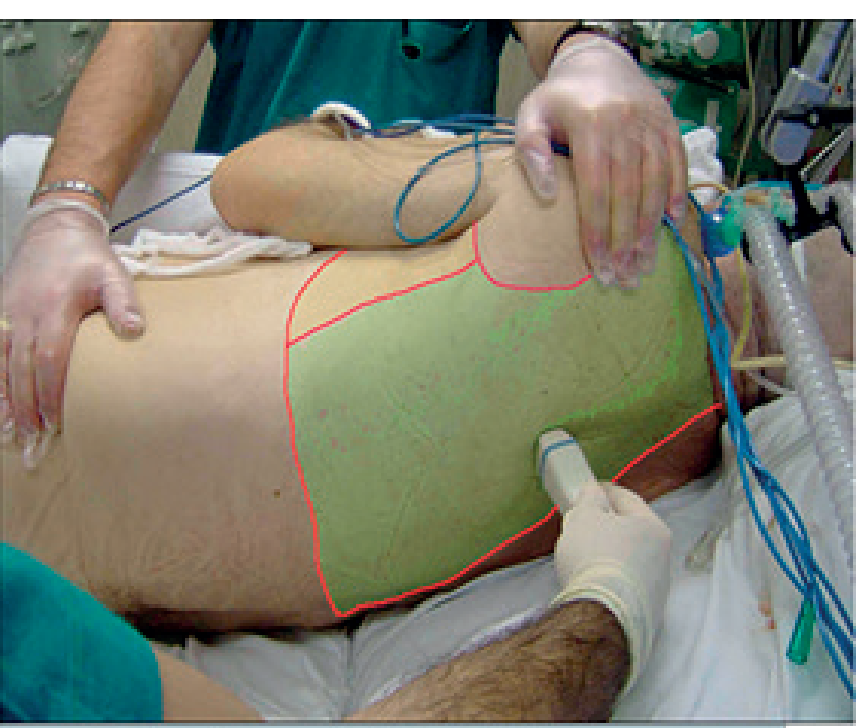

Probe: Linear probe (5-10 $\mathrm{MHz})$ Convex array probe (3-5 $\mathrm{MHz})$

Patient body position: Sitting/supine

\section{Anterior view}
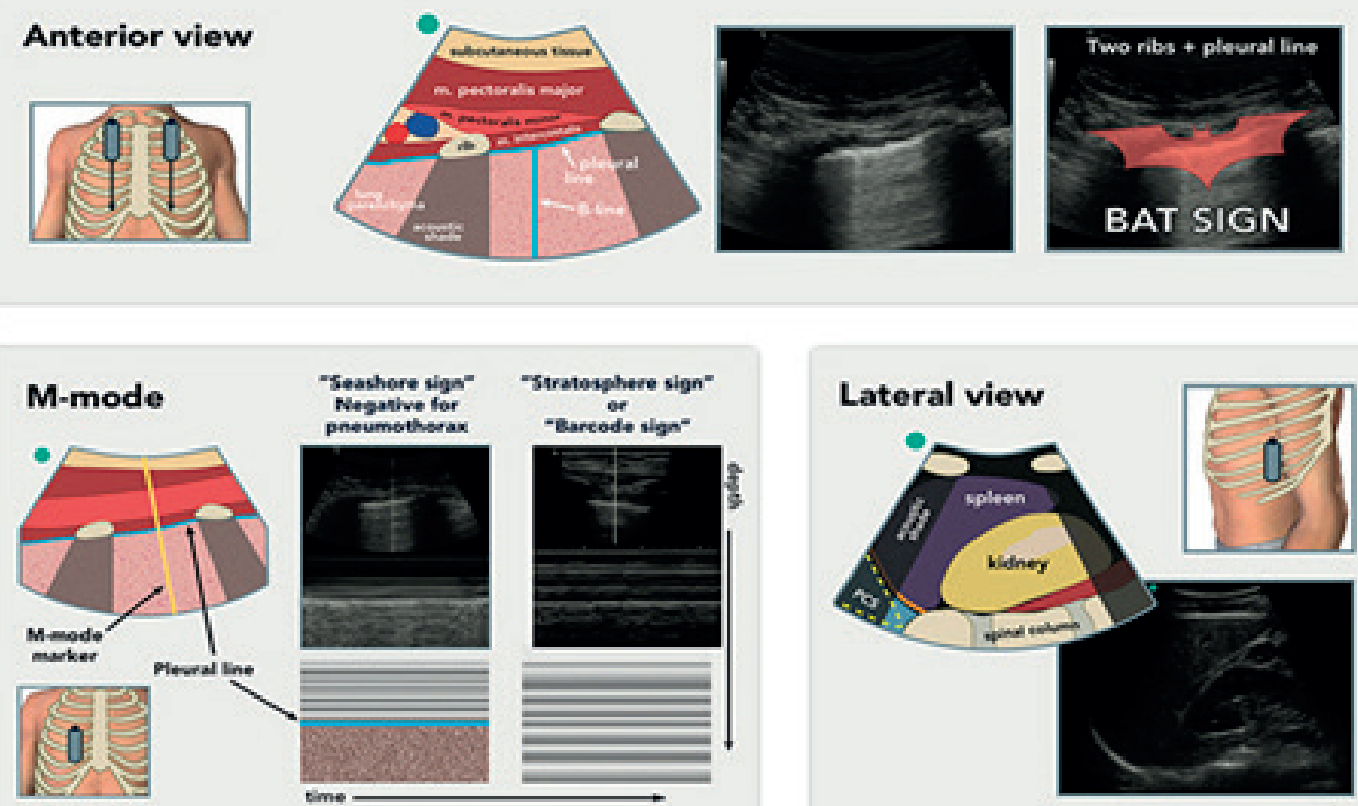

Slika 1: Izbor sonda, pozicija pacijenta za pregled i položaj pacijenta (3P)

Uloga ultrazvuka pluća u diferencijalnoj dijagnostici akutne respiratorne insuficijencije

Francuski lekar Lichtenstein je razvio dijagnostički algoritam koji omogućava nalaženje uzroka dispneje, vodeći se prethodno opisanim principima ultrazvuka pluća. Ime ovog algoritma je BLUE protokol (Bedside Lung Ultrasound in Emergency) (Slika 8)7. Ukratko, BLUE protokol koristi LUS i ultrazvuk vena za postavljanje diferencijalne dijagnoze akutne respiratorne insuficijencije ${ }^{8}$. $\mathrm{U}$ algoritmu se ultrazvukom pluća procenjuje postojanje tri osnovna nalaza: „klizanje” pleure, artefakti („A linije” $i$ „B linije”) $i$ alveolarna konsolidacija ili ple- uralni izliv. Pre sprovođenja algoritma, potrebno je razlikovati ultrazvučne nalaze koje je Lichtenstein kategorizovao u sedam bazičnih tipova, odnosno profila:

1. A profil predstavlja kombinaciju „klizanja” pleure i „A linija” na prednjem zidu. A profil predstavlja normalnu površinu pluća.

2. B profil odlikuje „klizanje” pleure i „B linije", odnosno artefakti po tipu repa komete.

3. A' profil je A profil uz odsustvo „klizanja” pleure.

4. B’ profil je B profil uz odsustvo „klizanja” pleure. 


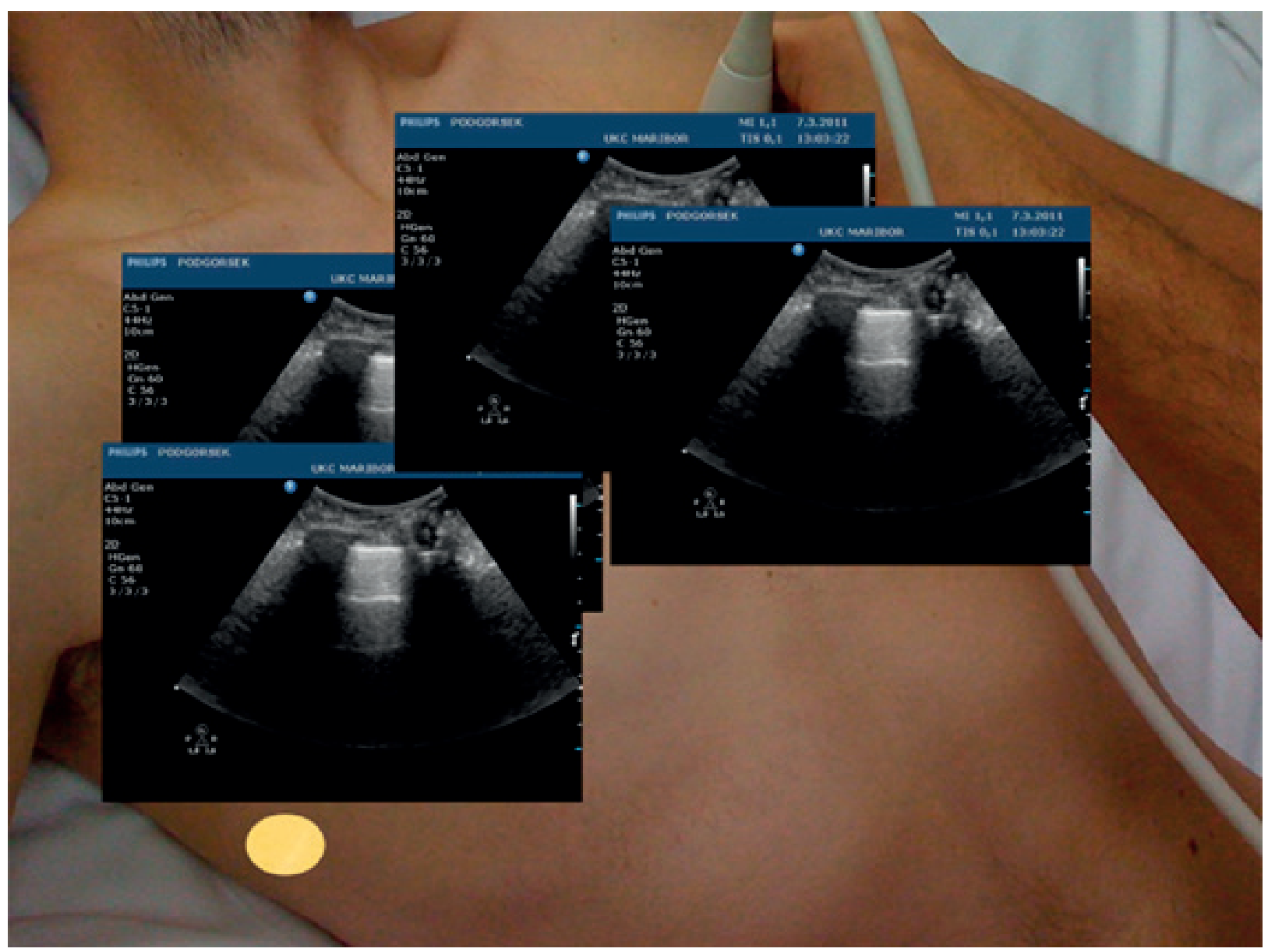

Slika 2: Normalan nalaz pluća sa paralelnim „A linijama”, obostrano

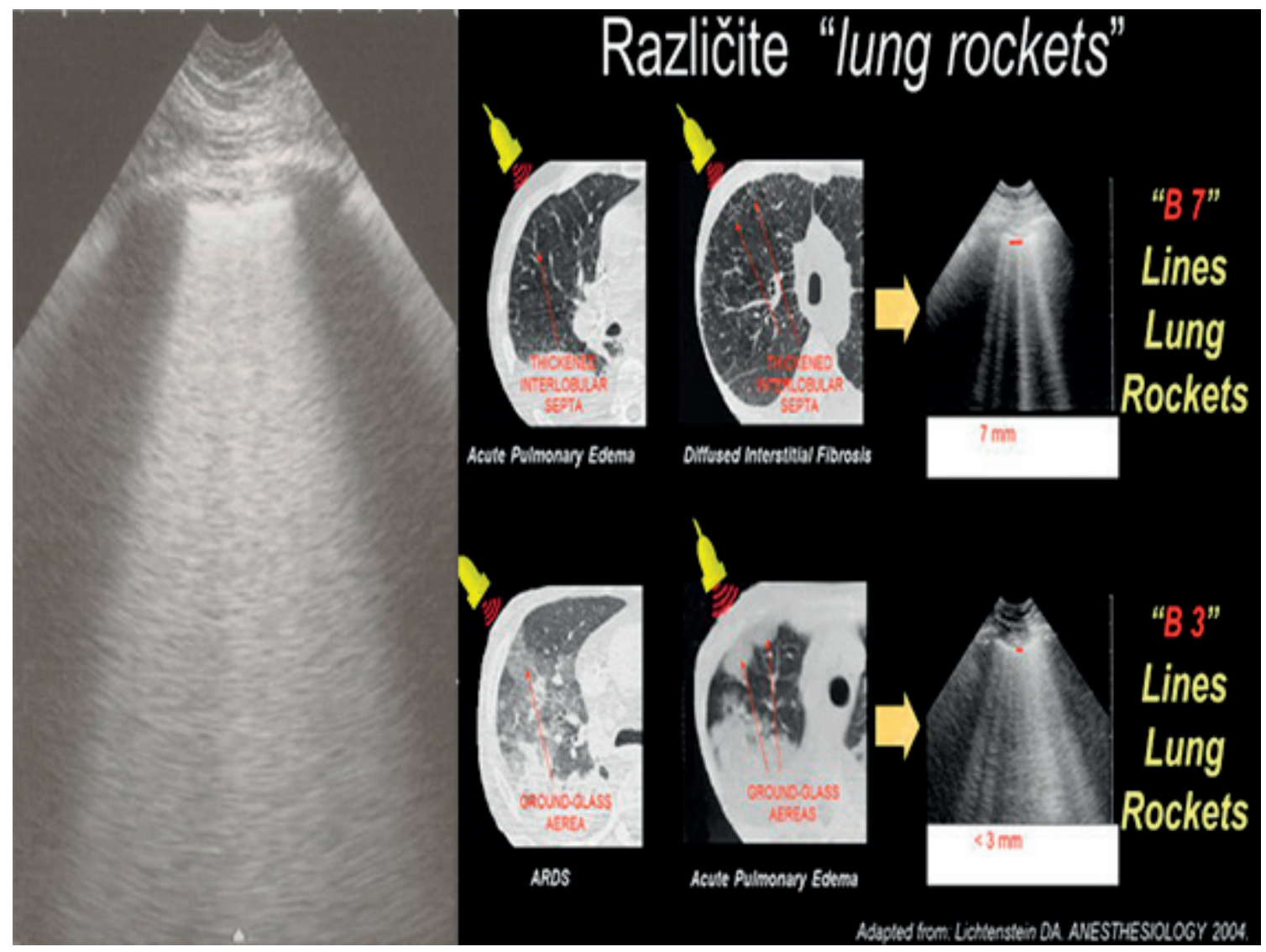

Slika 3: Intersticijalni sindrom - jasno vidljive hiperehogene „B linije” 


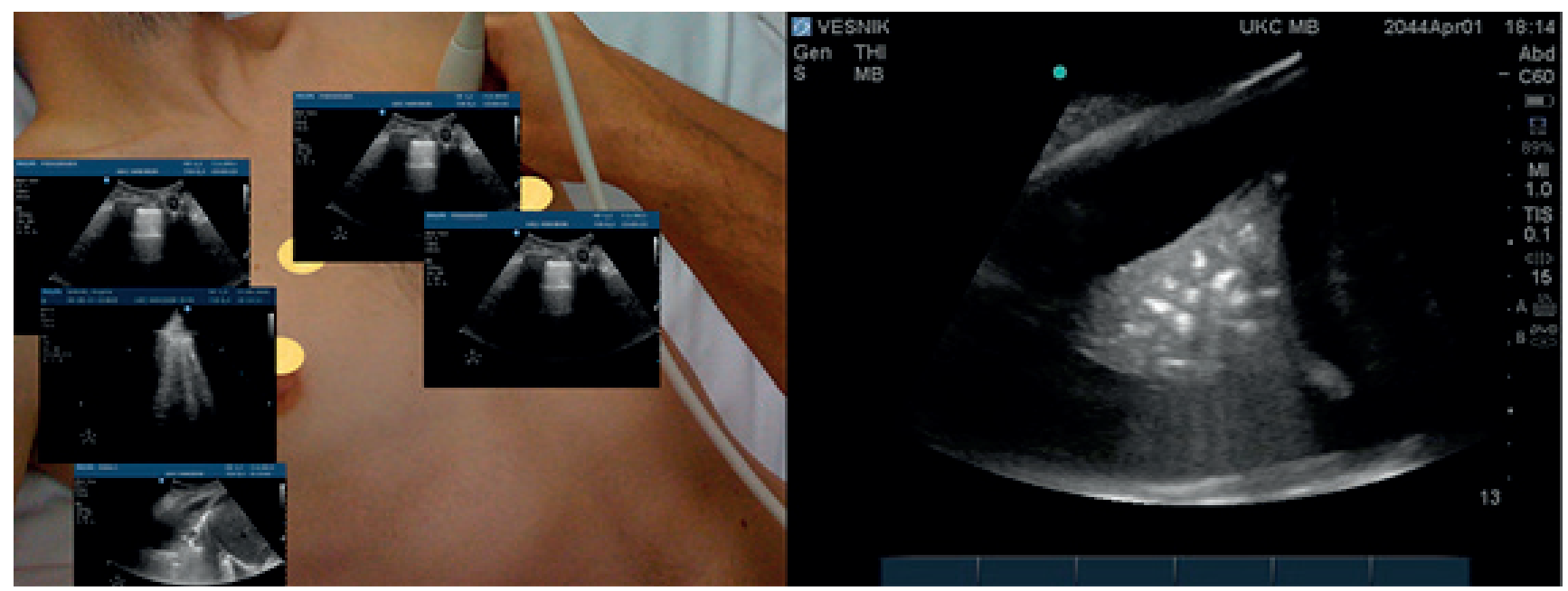

Slika 4: Intersticijalno-alveolarni sindrom - „B linije” jednostrano, ukazuju na konsolidaciju

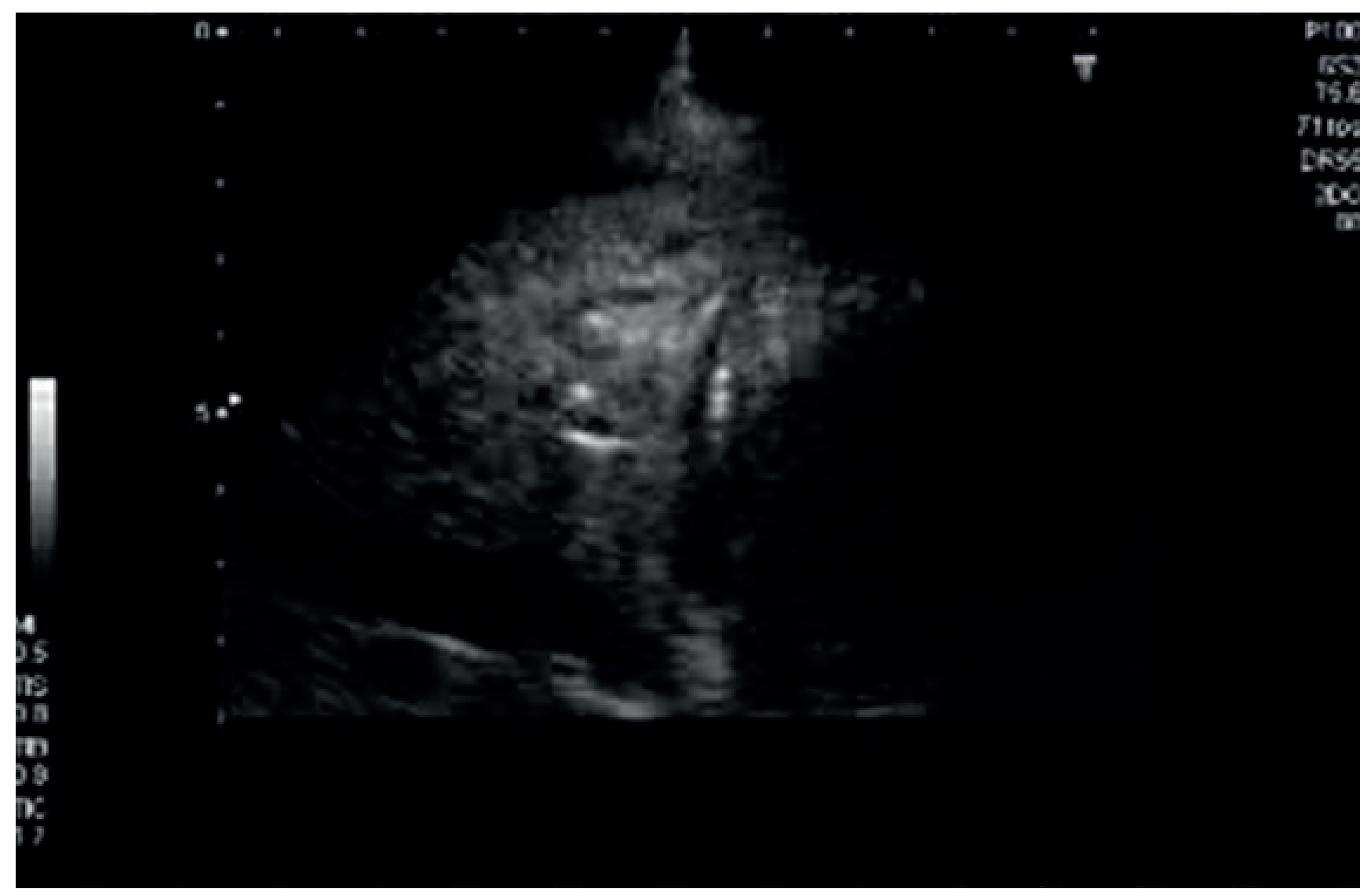

Slika 5: Alveolarni sindrom - znak hepatizacije

5. C profil predstavlja konsolidaciju pluća.

6. AB profil odlikuje A profil na jednom plućnom krilu i $B$ profil na drugom plućnom krilu.

7. PLAPS je engleska skraćenica za posterolateralni alveolarni i/ili pleuralni sindrom, što predstavlja alveolarnu konsolidaciju ili pleuralni izliv.

Šroka upotreba BLUE protokola se zasniva na njegovoj jednostavnosti. Na osnovu algoritma, prvo je potrebno da se utvrdi da li postoji „kliza- nje" pleure. Ukoliko je ovaj znak prisutan, isključena je dijagnoza pneumotoraksa. Sledeći korak je traženje anteriorne „B linije”. U ovom trenutku određujemo o kojem se tipu (profilu) ultrazvučnog nalaza radi. Ukoliko je prisutan A profil i postoji duboka venska tromboza, vrlo je verovatno da se radi o plućnom embolizmu. U slučaju da venska tromboza nije verifikovana, potrebno je da se potraži PLAPS. A profil sa PLAPS-om upućuje na pneumoniju, a bez PLAPS-a na egzacerbaciju hronične opstruktivne plućne bolesti ili astme. B profil 


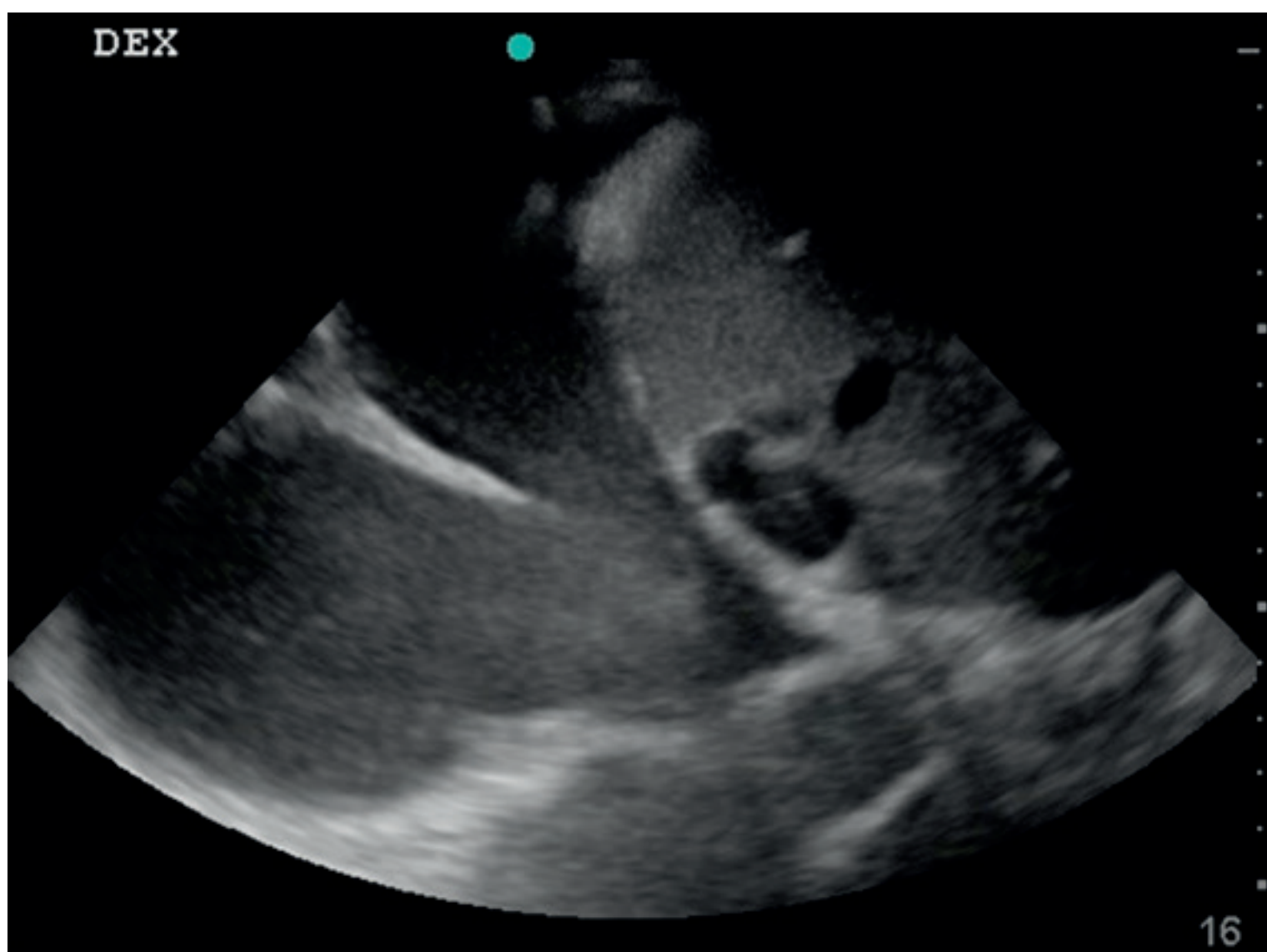

Slika 6: Pleuralni izliv

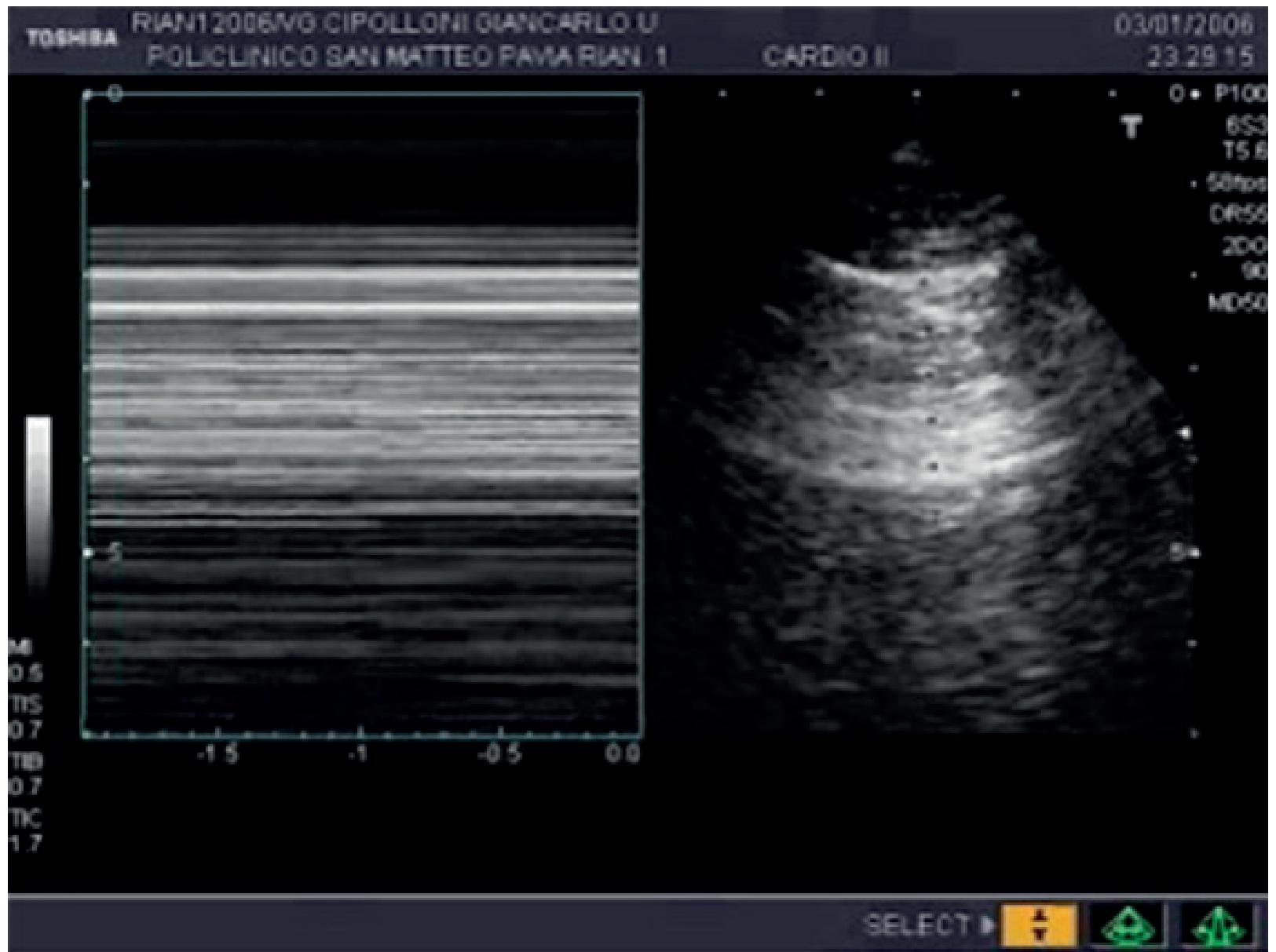

Slika 7: Znak „morske obale” na M modu 


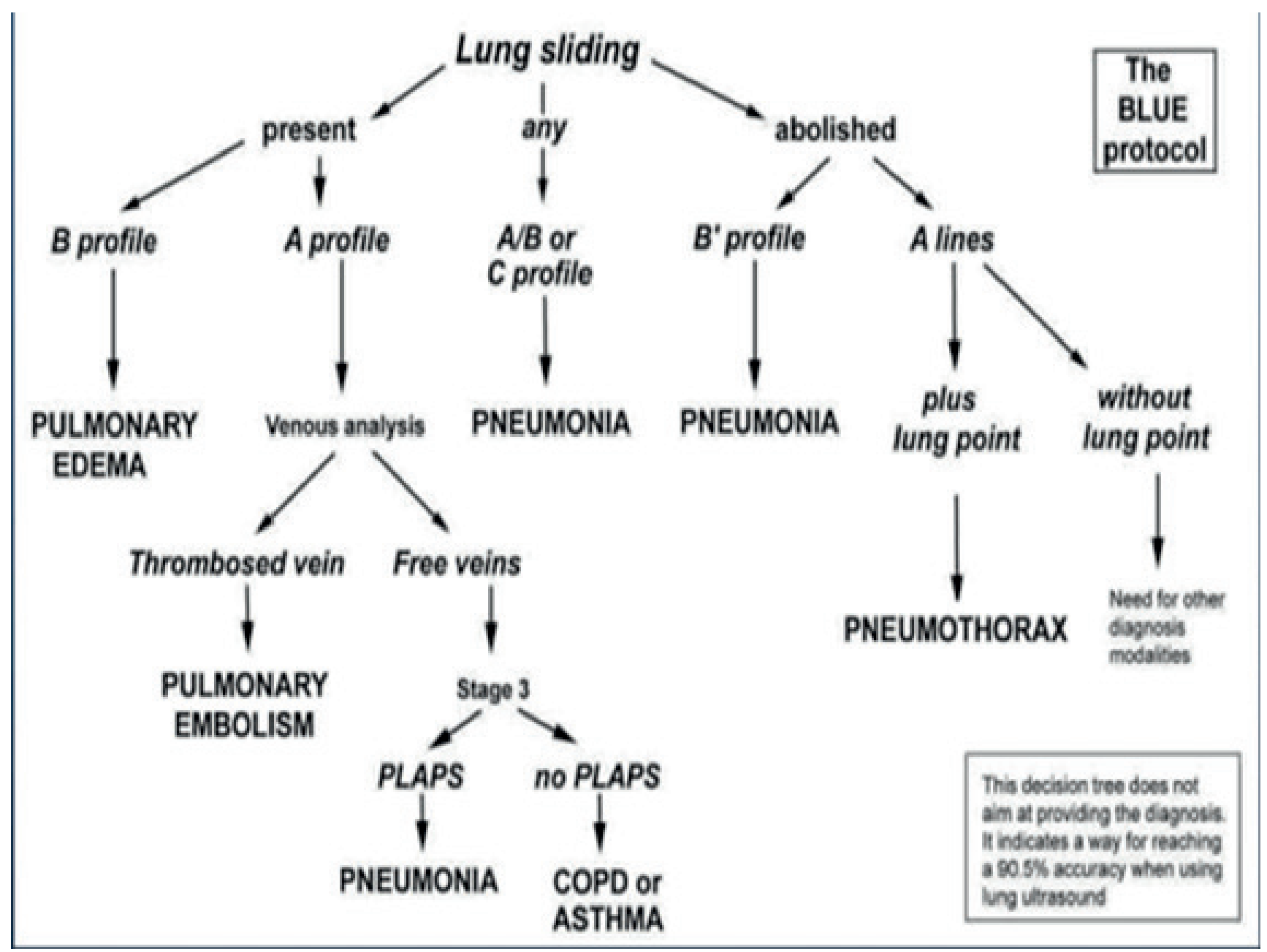

Slika 8: BLUE protokol - algoritam pokazuje diferencijalne dijagnoze akutne respiratorne insuficijencije

ukazuje na postojanje edema pluća. Karakteristike „B linija” pomažu pri razlikovanju kardiogenog plućnog edema i ARDS-a ${ }^{9}$. A/B, B' i C profil upućuju na pneumoniju. Ukoliko klizanje pleure nije prisutno i prisutne su A linije, potrebno je da se potraži granica pneumotoraksa. U odsutstvu granice, potrebne su dalje pretrage (A' profil).

BLUE protokol algoritam se pokazao kao tačan u pronalaženju uzroka akutne respiratorne insuficijencije kod oko $90 \%$ slučajeva $^{10}$. Senzitivnost ovog protokola je $97 \%$, a specifičnost $95 \%$ za plućni edem, dok je za plućnu emboliju senzitivnost $81 \%$, a specifičnost $99 \%$. U slučaju pneumonije senzitivnost je $89 \%$, a specifičnost $94 \%$. Kada je pneumoto- raks u pitanju, protokol daje senzitivnost od $88 \%$, a specifičnost je $100 \%$. Postavljanje dijagnoze za egzarcerbaciju HOBP ili teške astme ima senzitivnost $89 \%$, a specifičnost $97 \%$ (Tabela 1 ).

BLUE protokol može da se primeni za različite indikacije: trauma ${ }^{11}$, neonatologija ${ }^{12,13,14} \mathrm{i}$ ARDS. Ultrasonografija može biti korisna u merenju plućnog rekrutmenta ${ }^{15}$.

\section{FALLS protokol (Fluid Administration Limi- ted by Lung Sonography)}

Primena LUS-a uz pomoć FALLS protokola, koji se zasniva na Veilsovoj klasifikaciji šoka, pomaže u proceni potrebe za nadoknadom volume-

Tabela 1: Senzitivnost i specifičnost BLUE protokola u poređenju sa MDCT kao zlatnim standardom ${ }^{10}$

\begin{tabular}{|l|l|l|}
\hline Uzrok dispneje & Senzitivnost (\%) & Specifičnost (\%) \\
\hline Plućni edem & 97 & 65 \\
\hline Egzercerbacija HOBP ili teška astma & 89 & 97 \\
\hline Plućna embolija & 81 & 99 \\
\hline Pneumotoraks & 88 & 100 \\
\hline Pneumonija & 89 & 94 \\
\hline
\end{tabular}


$\mathrm{na}^{16}$. Kombinovanje BLUE protokola i orijentacione ehosonografije omogućava jednostavnu diferencijaciju vrsta šoka. On započinje potragom za perikardnim izlivom ili uvećanjem leve komore, a zatim za A' profilom. To može da isključi perikardnu tamponadu, emboliju pluća i pneumotoraks, što predstavlja uzorke opstruktivnog šoka. Ukoliko BLUE protokol ne pokaže „B linije”, možemo da isključimo plućni edem, a sledstveno tome i kardiogeni šok.

Pacijenti kod kojih je prisutan A profil se nazivaju FALLS responderi - imaće pozitivan odgovor na nadoknadu tečnosti. To upućuje na dijagnozu hipovolemijskog ili distributivnog šoka (septični šok). Ukoliko posle nadoknade tečnosti dođe do poboljšanja hemodinamskih parametara, u pitanju je hipovolemijski šok. Ako se radi o non-responderima, dijagnoza može da ide u pravcu distributivnog šoka. FALLS protokol omogućava brzu orijentaciju o primeni terapije, uključujući nadoknadu volumena, primenu vazopresora ili diuretika (Slika 9).

\section{Zaključak}

Ultrazvuk pluća u okviru BLUE protokola omogućava jednostavnu i brzu diferncijalnu dijagnozu akutne respiratorne insuficijencije. Brojne studije upućuju na značaj upotrebe LUS kod kritično obolelih pacijenata i u hitnim stanjima. Iz svega proističe zaključak da bi upotreba ultrasonografije pluća u našim ustanovama trebalo da bude češća. Takođe, potrebna su nova istraživanja na polju dijagnostike i upotrebe LUS-a u jedinici intezivnog lečenja.

\section{Izjave zahvalnosti}

Autori se zahvaljuju doktoru Gregoru Prošenu i Win Focus Sloveniji što su nam dozvolili da koristimo njihove slike.

\section{Literatura}

1. Saraogi A. Lung ultrasound: present and future. Lung India 2015; 32 (3):250-257.

2. Lichtenstein D, Meziere G. Relevance of lung ultrasound in the diagnosis of acute respiratory failure. Chest 2008; 134:117-125.

3. Lichtenstein D, Meziere G, Biderman P, et al. The lung point: an ultrasound sign specific to pneumothorax. Intensive Care Med 2000; 26:1434-1440.

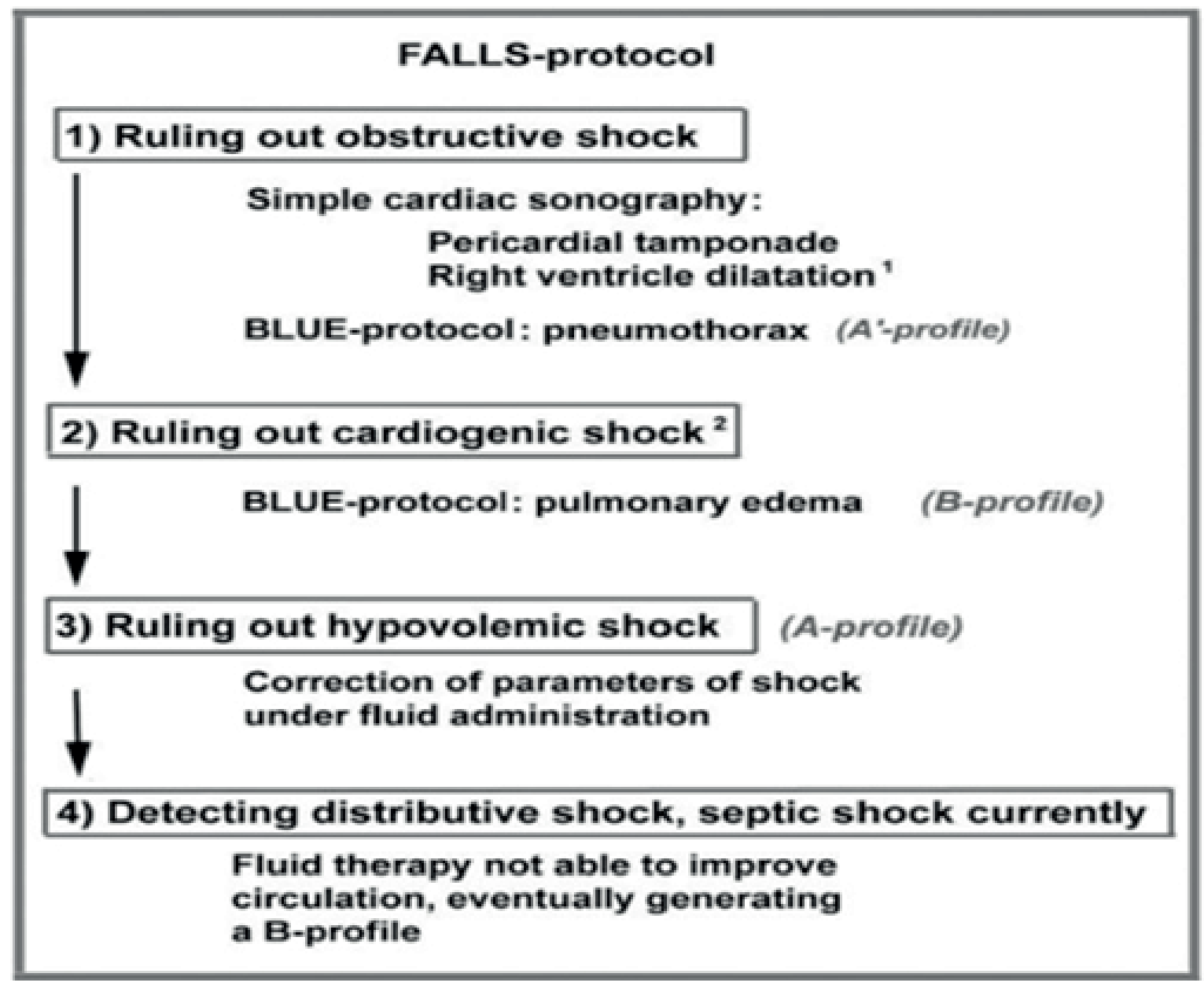

Slika 9: FALLS protokol 
4. Podlesnik A, Privsek M, Nikolic S, Arva V, Petrovic R, Banovic T, et al. PACE: POCUS Assisted Clinical Examination - A Modular Curiculum for teaching Point-of-Care Ultrasound to undregaduate med. Students. pace@medicinec. si,first edition, september 2016.

Stojadinovic M, Filipovic A, Zakošek M, Bulatovic D, Masulovic D. Lung ultrasound - part one. SJAIT 2018; 40(56):149-158.

5. Staub LJ, Biscaro RRM, Kaszubowski E, Maurici R. Chest ultrasonography for the emergency diagnosis of traumatic pneumothorax and haemothorax: A systematic review and meta-analysis. Injury 2018; 49(3):457-466.

6. Lichtenstein D, Mezière G. The BLUE-points: three standardized points used in the BLUE-protocol for ultrasound assessment of the lung in acute respiratory failure. Crit Ultrasound J 2011; 3:109-110.

7. Lichtenstein D, Mezière G. Relevance of lung ultrasound in the diagnosis of acute respiratory failure. The BLUE-protocol. Chest 2008; 134:117-125.

8. Lichtenstein D.Lung ultrasound in the critically ill. Curr Opin Crit Care 2014; 20(3):315-322.
9. Lichtenstein DA, Mezière GA. Relevance of lung ultrasound in the diagnosis of acute respiratory failure: the BLUE protocol. Chest 2008; 134(1):117-25.

10. Lichtenstein D, Courret JP. Feasibility of ultrasound in the helicopter. Intensive Care Med 1998; 24:1119.

11. Copetti R, Cattarossi L. The „double lung point”: an ultrasound sign diagnostic of transient tachypnea of the newborn. Neonatology 2007; 91:203-209.

12. Lichtenstein D. Ultrasound examination of the lungs in the intensive care unit. Pediatr Crit Care Med 2009; 10:693-698.

13. Lichtenstein D, Mauriat P. Lung ultrasound in the critically ill neonate. Curr Pediatr Rev 2012; 8:217-223.

14. Bouhemad B, Brisson H, Le-Guen M, et al. Bedside ultrasound assessment of positive end-expiratory pressure-induced lung recruitment. Am J Respir Crit Care Med 2011; 183:341-347.

15. Lichtenstein D. FALLS-protocol: lung ultrasound in hemodynamic assessment of shock. Heart Lung Vessels 2013; 5:142-147. 